\title{
Fluorescent ligands for studying neuropeptide receptors by confocal microscopy
}

A. Beaudet ${ }^{1}$, D. Nouel ${ }^{1}$, T. Stroh ${ }^{1}$, F. Vandenbulcke ${ }^{1}$,

C. Dal-Farra² and J.-P. Vincent ${ }^{2}$

\author{
${ }^{1} M$ ontreal Neurological Institute, M cGill U niversity, Montreal, Q uebec, Canada \\ 2Institut de Pharmacologie Moléculaire et Cellulaire du CNRS, \\ Université de Nice-Sophia Antipolis, Valbonne, France
}

\section{Correspondence \\ A. Beaudet \\ Montreal Neurological Institute 3801 University Street \\ Montreal, Quebec \\ Canada H3A 2B4 \\ Fax: + 1-514-398-5871 \\ E-mail: mcin@ musica.mcgill.ca}

Presented at the International Symposium: Biological Applications of Confocal Microscopy, Belo Horizonte, MG, Brasil, April 6-8, 1998.

Personal work referred to in the text was made possible by a grant from the Medical Research Council of Canada, and by fellowships from the Fonds de la Recherche en Santé du Québec, the Deutsche Forschungsgemeinschaft and the Fondation pour la Recherche Médicale, and by a France-Q uebec International exchange program.

Received May 14, 1998 Accepted June 3, 1998

\section{Abstract}

This paper reviews the use of confocal microscopy as it pertains to the identification of G-protein coupled receptors and the study of their dynamic properties in cell cultures and in mammalian brain following their tagging with specific fluorescent ligands. Principles that should guide the choice of suitable ligands and fluorophores are discussed. Examples are provided from the work carried out in the authors' laboratory using custom synthetized fluoresceinylated or BODIPYtagged bioactive peptides. The results show that confocal microscopic detection of specifically bound fluorescent ligands permits high resolution appraisal of neuropeptide receptor distribution both in cell culture and in brain sections. Within the framework of time course experiments, it also allows for a dynamic assessment of the internalization and subsequent intracellular trafficking of bound fluorescent molecules. Thus, it was found that neurotensin, somatostatin and muand delta-selective opioid peptides are internalized in a receptordependent fashion and according to receptor-specific patterns into their target cells. In the case of neurotensin, this internalization process was found to be clathrin-mediated, to proceed through classical endosomal pathways and, in neurons, to result in a mobilization of newly formed endosomes from neural processes to nerve cell bodies and from the periphery of cell bodies towards the perinuclear zone. These mechanisms are likely to play an important role for ligand inactivation, receptor regulation and perhaps also transmembrane signaling.

\section{Introduction}

There has been a long history of attempts at conjugating fluorescent molecules to receptor ligands with the aim of identifying specific neurotransmitter binding sites (for a review, see 1). However, many of these attempts were defeated by the lack of suitable probes as well as by the insensitivity of avail-

\author{
Key words \\ - Neurotensin \\ - Somatostatin \\ - Opioids \\ - Internalization \\ - Endocytosis \\ - Confocal microscopy
}

able fluorescence detectors. More recently, the conjugation of new, high-affinity receptor ligands to fluorophores of high stability and fluorescent yield (including BODIPY (1) and cyanine dyes (2)) has opened the range of available fluorescent probes for receptor studies. Most importantly, the development of highly sensitive detection methods, and namely of confocal microscopy, has 
provided us with powerful and resolving approaches for studying receptors and receptor-mediated mechanisms in living tissue.

\section{Applications of fluorescent ligands to the study of receptor-ligand interactions}

There are several ways in which fluorescent ligands may be applied to the study of neurotransmitter receptors. These include: 1) classical binding studies in which radioactive probes are replaced with fluorescent ones and specifically bound ligand is detected using fluorescence polarization assays, 2) flow cytometric studies in which fluorescence-activated cell sorters (FACS) are used for assessing specific cell surface ligand binding in dissociated cells $\left(\right.$ at $4{ }^{\circ} \mathrm{C}$ ) or for demonstrating ligand internalization within transfected cells (at $37^{\circ} \mathrm{C}$ ), and 3 ) photobleaching experiments in which the bleaching of certain ligand molecules (which are only fluorescent when bound) is used to study the rate of recovery of fluorescence after bleaching and hence to provide information on the association of the fluorescent ligand. In the present review, we will focus on the use of confocal microscopy for: 1) assessing the binding of fluorescent ligands to their receptors in isolated cells in culture or in whole brain sections, 2) visualizing ligand internalization and trafficking in transfected cells and live brain slices, and 3) identifying intra-cellular compartments of ligand sequestration.

\section{Selection of a fluorescent ligand}

The choice of a fluorescent ligand should take into account the metabolic and pharmacological properties of the compound to be tagged as well as the biophysical properties of the fluorophore.

The ligand to be tagged may be an agonist or an antagonist. The latter usually of- fers a higher affinity, and therefore provides for a better signal to noise ratio, than agonists. However, antagonists are ill suited for the study of receptor dynamics as they usually do not internalize (3). They do, however, reportedly induce receptor clustering (3). Metabolically stable analogs may prove more advantageous than native ligands for studying ligand-receptor interactions in vivo. Thus, the use of the stable somatostatin (SRIF) analog, BODIPY-D-Trp8-SRIF, has allowed us to study SRIF binding and internalization both in transfected cells (4) and in neurons (our unpublished data) without having to resort to catabolic enzyme inhibitors. The downside of these compounds, however, is that their intracellular fate may not faithfully mimic that of the native peptide.

Ideally, a fluorescent ligand should retain as much as possible of the affinity and selectivity of the untagged agonist. In practice, however, the addition of a fluorescent moiety will often affect the binding affinity of the ligand. This loss of affinity will usually depend on the site at which the fluorophore is tagged to the fluorescent probe (5). It will also vary according to the fluorophore chosen. Thus, whereas the addition of fluorescein (FITC) or of BODIPY moieties to DTrp8-somatostatin (D-Trp8-SRIF) only slightly reduces the affinity of the ligand in brain membrane preparations (4), the tagging of a Cy 3.5 fluorophore to the same molecule reduces its binding affinity by almost an order of magnitude (our unpublished data). This loss in affinity, however, is also a function of the intrinsic properties of the ligand and of its pharmacophore, as the neuropeptide neurotensin (NT) may be tagged with any of the FITC, BODIPY or Cy 3.5 moieties without losing its affinity for the NT receptor (our unpublished data).

In all cases, it is imperative to test the pharmacological properties of any new fluorescent ligand by determining its radioligand binding displacement properties on membranes from cells expressing the native re- 
ceptor or transfected with the recombinant receptor of interest (4-6). These binding experiments should be complemented by imaging studies on whole cells that either naturally express the receptor under study or are transfected with the appropriate recombinant DNA to measure concentration-dependent binding in the presence and absence of nonlabeled competitors. Whenever possible, the biological relevance of the fluorescent ligand should also be tested, either in cell culture or in slice preparations (7).

For the reasons stated above, the choice of a fluorophore will be predicated on its compatibility with the preservation of the pharmacological properties of the ligand. Within this frame of reference, preference should be given to fluorophores with high fluorescent yield and resistance to photobleaching. Both BODIPY and Cy compounds are particularly interesting in this regard. One should also ensure that the fluorescent ligand remains hydrophilic, which is critical for the localization of cell surface receptors.

Fluorescent ligands have so far been developed against a variety of neuroreceptors, including $\alpha$-adrenoceptors (1), $\beta$-adrenoceptors $(8,9)$, benzodiazepine receptors (10), nicotinic (11) and muscarinic (12) acetylcholine receptors, and D1 (13) and D2 $(13,14)$ dopamine receptors. In the present review, we will focus on the use of peptidic probes as developed by our group for studying neuropeptide-receptor interactions in cell cultures and mammalian brain sections. Several other studies have made use of fluorescent probes for studying neuropeptide-receptor interactions. These include studies on substance P $(15,16)$, angiotensin II (17), thyrotropin-releasing hormone (18), opioid $(19,20)$, cholecystokinin (21), gonadotropinreleasing hormone (22), vasopressin (23) and gastrin-releasing peptide (24) receptors. The reader is referred to these publications for further information.

\section{Fluorescent peptide binding to cells in culture and to whole brain slices}

Confocal microscopic analysis of specific fluorescent peptide binding may be used for static assessment of the cellular distribution of neuropeptide receptor distribution in whole cells in culture or in frozen brain sections.

\section{Binding to cultured cells}

The binding of FITC- and BODIPY-labeled neurotensin (fluo-NT), of FITC- and BODIPY-labeled D-Trp8-somatostatin (fluoSRIF), of BODIPY-labeled dermorphin (fluodermorphin) and of BODIPY-labeled deltorphin (fluo-deltorphin) was examined in COS-7 cells transfected with recombinant DNA encoding high- or low-affinity NT receptors (fluo-NT), sst1, sst2A or sst5 SRIF receptors (fluo-SRIF), and mu (fluo-dermorphin) or delta (fluo-deltorphin) opioid receptors $(4,5,25$; our unpublished data). Binding of fluo-NT was also assessed in cells naturally expressing the high-affinity neurotensin receptor (NT-1; SN17 neuron-neuroblastoma hybrid cells (26); primary neurons in culture (27)) or the low-affinity NT receptor (NT-2; astrocytes in culture (27)). Binding was carried out at $4^{\circ} \mathrm{C}$ or at $37^{\circ} \mathrm{C}$ in the presence of the endocytosis inhibitor, phenylarsine oxide (PAO), to prevent ligand sequestration and/or internalization. Concentrations used ranged between 1 and $20 \mathrm{nM}$. Nonspecific binding was determined by coincubating with a 100-500-fold excess of a nonfluorescent peptide or of a relevant antagonist. Confirmation that the bound ligand was restricted to the cell surface was obtained by subjecting labeled cells to a hypertonic acid wash $(0.5 \mathrm{M} \mathrm{NaCl}, \mathrm{pH}=4.0)$ documented to strip surface-bound peptide off the cells (28). Time for reaching equilibrium was determined in parallel experiments using the corresponding iodinated peptide. 
Figure 1 - Binding of fluo-NT to COS-7 cells transfected with cDNA encoding the low-affinity NT receptor (NT-2). Cells were incubated for $30 \mathrm{~min}$, at $4^{\circ} \mathrm{C}$, in the presence of $10 \mathrm{nM}$ fluo-NT. Labeling is strictly membranebound and forms a more or less homogeneous pericellular ring. Scale bar: $5 \mu \mathrm{m}$.

Figure 2 - Effect of the endocytocis inhibitor, phenylarsine oxide (PAO), on the cell surface distribution of bound fluo-dermorphin. COS-7 cells transfected with cDNA encoding the mu opioid receptor were incubated for $45 \mathrm{~min}$, at $37^{\circ} \mathrm{C}$, with $10 \mathrm{nM}$ fluo-dermorphin in the presence of $10 \mu \mathrm{M}$ PAO. Note how the bound fluorescent molecules form a single large cluster at one pole of the cell (arrow). Scale bar: $5 \mu \mathrm{m}$.

Figure 3 - Distribution of fluo-NTlabeled NT-2 receptors on the surface of an astrocyte in culture following 60-min incubation at $37^{\circ} \mathrm{C}$ with $20 \mathrm{nM}$ fluo-NT. In these cells, which express but do not internalize NT-2 receptors, surface-bound molecules form numerous polymorphic clusters. This labeling is entirely suppressed by a hypertonic acid wash. Scale bar: $20 \mu \mathrm{m}$.
In all transfected cell systems, fluorescent peptides bound at $4^{\circ} \mathrm{C}$ formed at equilibrium a more or less homogenous pericellular ring (Figure 1). This labeling was specific in that it was no longer apparent when the incubations were carried out in the presence of an excess of nonlabeled peptide. It was also exclusively surface-bound, as determined by serial confocal sectioning through the cell and confirmed by its complete disappearance following a hypertonic
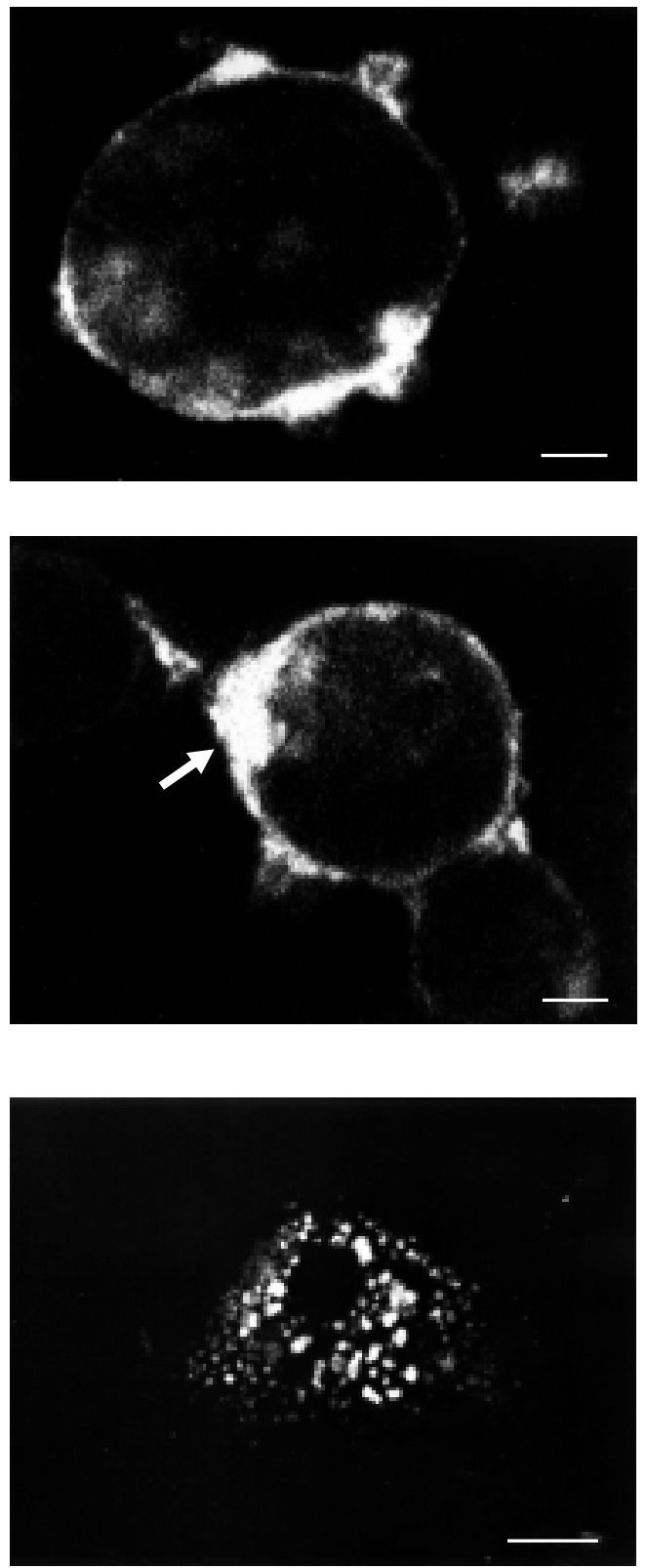

acid wash. In COS- 7 cells incubated at $37^{\circ} \mathrm{C}$ in the presence of an endocytosis inhibitor, specific fluorescent labeling was also confined to the cell surface, but was usually more prevalent at one pole of the cell (Figure 2 ). This capping of bound fluorescence was taken to reflect cell surface clustering of receptor complexes under conditions of impeded internalization $(5,26)$.

When the same experiments were carried out in cells naturally expressing the receptor, cell surface binding at $4{ }^{\circ} \mathrm{C}$ took the form of small fluorescent hot spots haphazardly distributed upon the surface of the cells. The size and shape of these fluorescent hot spots, corresponding to ligand-receptor clusters, varied according to the type of cell and/or receptor expressed. Thus, in $\mathrm{SN}-17$ cells, which express the NT-1 receptor, these clusters were small and rounded (26). By contrast, in astrocytes, which express the NT-2 receptor, these surface clusters were larger and more geometric in shape (27; Figure 3 ). However, when incubated at $37^{\circ} \mathrm{C}$ in the presence of PAO, naturally expressing cells exhibited the same capping phenomenon as observed in transfected cells.

The differences between patterns generated in naturally expressing versus transfected cells at $4{ }^{\circ} \mathrm{C}$ probably reflect disparities in receptor densities (the concentration of receptors in transfected cells being too high for one to resolve individual clusters). They could also reflect differences in clustering properties, but this appears unlikely given the similarity of the patterns observed at $37^{\circ} \mathrm{C}$ in the presence of PAO. In any event, the present results suggest that even at $4{ }^{\circ} \mathrm{C}$, the membrane retains a fluidity compatible with cell surface clustering of receptor-ligand complexes.

\section{Binding to frozen brain sections}

We have recently resorted to this approach for localizing SRIF binding sites at the cellular level in the rat mediobasal hypo- 
thalamus. The labeling technique is the same as those currently used for assessing receptor distributions by autoradiography (29). The advantage of using fluorescent over radioactive ligands is that they provide higher resolution and speedier results. They are also considerably less sensitive, however, and ligand concentrations may have to be increased accordingly.

Briefly, $20 \mu \mathrm{m}$-thick sections from the mediobasal hypothalamus were incubated for $45 \mathrm{~min}$ at $4^{\circ} \mathrm{C}$ with $40 \mathrm{nM}$ fluo-SRIF, in the presence (nonspecific binding) or the absence (specific binding) of a hundred-fold excess of nonfluorescent ligand. In sections incubated with fluo-SRIF alone, both conventional epifluorescence and confocal microscopy revealed selective binding of the fluorescent compound in the arcuate nucleus. This binding was specific, as demonstrated by the fact that sections incubated in the presence of a hundred-fold excess of nonlabeled ligand showed only background fluorescence. At the regional level, the labeled pattern was comparable to that previously observed by autoradiography using ${ }^{125}$ I-SRIF (30). However, confocal microscopy allowed for a more clear-cut localization of the ligand to small neuronal perikarya distributed throughout the structure. Furthermore, serial optical sectioning of the labeled sections revealed that the label was not confined to the cell surface but was present throughout the cytoplasm of the labeled perikarya.

\section{Internalization and intracellular trafficking of receptor-ligand complexes}

The application of confocal microscopy to the visualization of specifically bound fluorescent peptides has proven most powerful for studying internalization and trafficking of receptor-ligand complexes into their target cells. These processes may be studied both in live cells in culture and in whole brain slices maintained in a superfusion system.

\section{Cell culture studies}

We compared the internalization and intracellular trafficking of fluo-NT via highaffinity NT receptors (NT-1), of fluo-SRIF via various SRIF receptor subtypes, and of fluo-dermorphin and fluo-deltorphin via $\mu$ and $\delta$ opioid receptors, respectively, in COS7 cells transfected with cDNA encoding the appropriate receptor. Internalization was demonstrated by incubation with the appropriate fluorescent ligand at $37^{\circ} \mathrm{C}$, followed by a series of hypertonic acid washes to strip off surface-bound ligand and visualization of acid-wash resistant labeling by confocal microscopy. Incubations with ${ }^{125}$ I-labeled peptide analogues were carried out in parallel to provide a quantitative measure of ligand binding and of receptor-mediated endocytosis. Confirmation that the internalization was endocytic in nature was obtained by carrying out the incubations in the presence of the endocytosis inhibitor, PAO.

Incubation of COS-7 cells transfected with cDNA encoding the NT-1 receptor for 0-60 min with $10 \mathrm{nM}$ fluo-NT resulted in a rapid build-up of acid-resistant intracellular fluorescence. Parallel experiments using ${ }^{125} \mathrm{I}-$ NT confirmed that this internalization process was both rapid $(\mathrm{t} 1 / 2=10 \mathrm{~min})$ and efficient ( $80 \%$ of total surface binding internalized by one hour). At short time intervals (between 0 and $20 \mathrm{~min}$ ), the label formed small "hot spots" distributed throughout the cytoplasm of the cells, but sparing the nucleus (Figure 4). At later time points ( $>20$ $\mathrm{min}$ ), these endosome-like particles decreased in number and progressively clustered towards the center of the cells, next to the nucleus.

In the case of somatostatin (SRIF), the same type of experiments were carried out on COS cells transiently transfected with cDNAs encoding SRIF receptor subtypes 
Figure 4 - Distribution of internalized fluo-NT in COS-7 cells transfected with cDNA encoding the high-affinity NT receptor (NT1). Cells were incubated for 20 min with $20 \mathrm{nM}$ fluo-NT and subjected to a hypertonic acid wash. Internalized ligand forms small, rounded hot spots that pervade the cytoplasm but spare the nucleus (n). Scale bar: $10 \mu \mathrm{m}$.

Figure 5 - COS- 1 cells transfected with CDNA encoding the sst2A somatostatin (SRIF) receptor and incubated for 30 min with $20 \mathrm{nM}$ fluo-SRIF at $37^{\circ} \mathrm{C}$. The intracellular labeling pattern, seen here after wash-out of surface-bound ligand with hypertonic acid buffer, is similar to that observed with fluo-NT in NT-1transfected COS-7 cells (see Figure 4). Small, intensely labeled endosome-like particles pervade the cytoplasm of the cells. n, Nucleus. Scale bar: $10 \mu \mathrm{m}$.

Figure 6 - Internalization of fluoSRIF in COS-7 cells transfected with CDNA encoding the sst5 SRIF receptor. After $20 \mathrm{~min}$ of incubation, the bulk of the ligand is still confined to a sub-plasmalemmal zone. Compare the distribution of the acid-washable fraction of the ligand, as seen here, with that evident at the same time point in Sst2A-transfected cells. Scale bar: $10 \mu \mathrm{m}$.
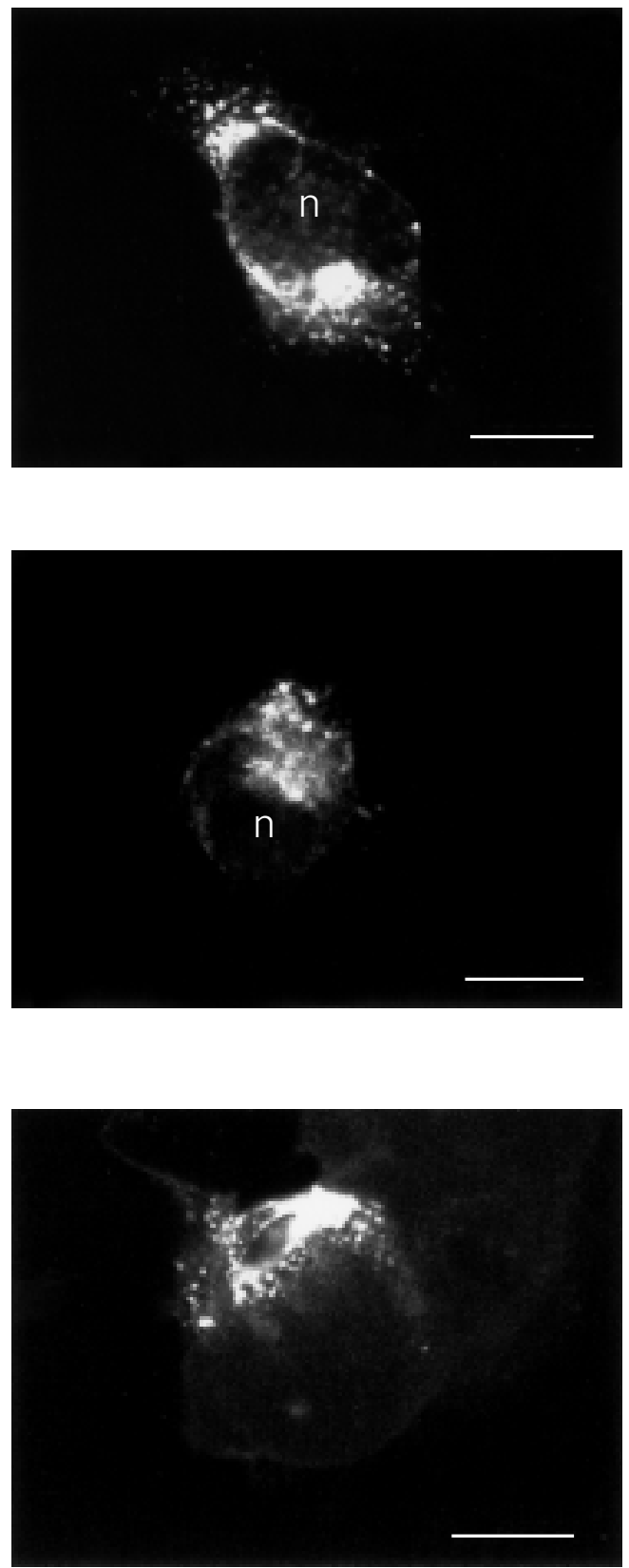

sst1, sst2A or sst5. Biochemical experiments using the radioactive SRIF analogue ${ }^{125} \mathrm{I}-$ $\mathrm{Tyr}^{0}{ }^{-}\left[\mathrm{D}-\mathrm{Trp}^{8}\right]$ SRIF showed that internalization of SRIF was dependent on the receptor subtype, with sst2A mediating the internalization of radioiodinated $\mathrm{Tyr}^{0}-\left[\mathrm{D}-\mathrm{Trp}^{8}\right] \mathrm{SRIF}$ as effectively as did NT-1 for fluo-NT (approximately $80 \%$ of total radioactivity bound), whereas sst1 internalized only very little ( $<10 \%$ of total radioactivity bound; 4$)$.
The capacity of internalization via sst5 was intermediate between sst 1 and sst $2 \mathrm{~A}$ receptor subtypes (our unpublished data).

By confocal microscopy, incubation of sst 1 -transfected cells at $37^{\circ} \mathrm{C}$ with fluo-SRIF for 0-60 min gave rise to a pericellular ringlike pattern of labeling. This labeling pattern remained remarkably constant with time, closely resembling the one obtained after incubation of peptide-receptor-transfected cells at $4^{\circ} \mathrm{C}$ (see above). However, it was entirely preserved after a hypertonic acid wash indicating that it was not surface bound but sub-plasmalemmal (4).

COS cells transfected with cDNA encoding sst $2 \mathrm{~A}$, on the other hand, exhibited fluorescent labeling throughout their cytoplasm, as observed after incubation with fluo-NT. As with fluo-NT, this labeling was highly punctate, suggesting that the label had been sequestered in small membrane-bound compartments (Figure 5). The size of these particles varied significantly with time as their mean surface progressively increased in the course of the experiment. At the same time, they redistributed from a peripheral distribution at short incubation times (1-5 min) by invading the whole cytoplasm and converging towards the nucleus at later stages of the experiment (4).

The intracellular labeling observed in COS cells transfected with cDNA encoding sst5 more closely resembled the eccentric pattern of labeling observed in sst1-transfected cells than in cells transfected with sst2A, at least at early time points (0-20 min; Figure 6). However, at later time intervals ( $>20 \mathrm{~min}$ ) the ligand started to pervade the cytoplasm within small endosome-like particles as seen with the sst2A sub-type.

The intracellular distribution of fluodermorphin and fluo-deltorphin within COS7 cells transfected with $\mu$ and $\delta$ opioid receptors, respectively, also varied markedly with time. After short durations of incubation, both fluorescent markers were clustered at one pole of the cell in the immediate vicinity 
of the plasma membrane. After $30 \mathrm{~min}$, the label had taken on the shape of small fluorescent particles in the cytoplasm. These were, however, still excentrically clustered. After $60 \mathrm{~min}$ the label finally pervaded the entire cytoplasm sparing the nucleus but remaining highly punctate. By this time, differences between fluo-deltorphin and fluo-dermorphin-labeled endosome-like particles became apparent in that the latter were on average larger and less numerous (5).

In order to directly assess possible differences in the pathways through which $\mu$ and $\delta$ opioid receptors had internalized their respective ligands, COS cells were co-transfected with cDNA encoding $\mu$ and $\delta$ opioid receptors. Subsequently, the cells expressing both types of opioid receptors were simultaneously incubated with BODIPY Green-deltorphin and BODIPY Red-dermorphin for $90 \mathrm{~min}$ at $37^{\circ} \mathrm{C}$. Images were then acquired through the distinct red and green excitation/emission channels of the confocal microscope. The single images showed patterns of labeling equivalent to those found in singly transfected cells. Superimposition of the images, however, showed only partial overlap of red and green fluorescent particles indicating that the $\mu$ and $\delta$ fluorescent ligands were partly sequestered in distinct compartments. Interestingly, the bulk of distinct green and red particles were small and predominantly located in peripheral zones of the cytoplasm whereas double-labeled endosome-like particles were concentrated in the center of the cell, suggesting that dermorphin and deltorphin were internalized initially via separate compartments that eventually joined in the course of intracellular trafficking.

These findings indicate that neuropeptide receptors are internalized following ligand binding when ectopically expressed in transfected epithelial cells. More importantly, however, they demonstrate that the internalization of individual ligands is differentially regulated according to receptor

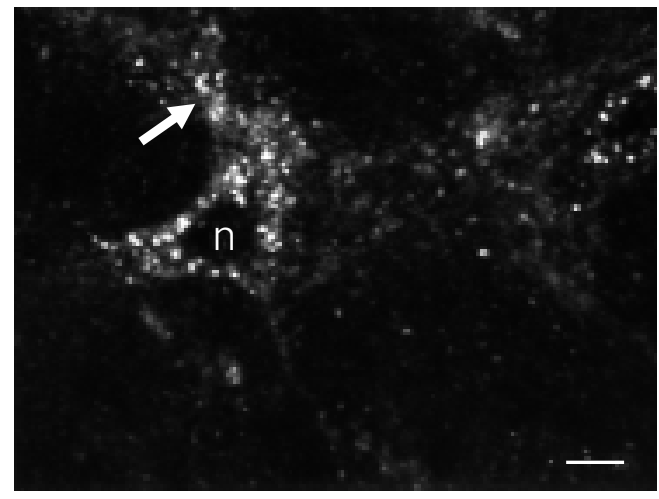

Figure 7 - Fluo-NT-labeled neuron in the ventral tegmental area of an adult rat brain. Sections from the ventral midbrain were superfused during 3 min with 20 nM fluo-NT at $37^{\circ} \mathrm{C}$, rinsed for 10 min in buffer, fixed with $4 \%$ paraformaldehyde and optically sectioned. Internalized ligand molecules are evident within endosome-like organelles throughout the perikaryon sparing the nucleus (n). Labeled endosomes are also evident within the proximal processes of the cell (arrow). No labeling was apparent when the incubation was carried out at $4^{\circ} \mathrm{C}$ or at $37^{\circ} \mathrm{C}$ in the presence of an excess of nonfluorescent NT. Scale bar: $15 \mu \mathrm{m}$.

In order to determine whether neuropeptides were internalized into live neuronal cells with the same efficiency and according to comparable sequestration patterns as they did in heterologous transfection systems, we examined the binding and internalization of fluo-NT in live brain slices ( $300 \mu \mathrm{m}$ thick) superfused in vitro in a recording chamber system. We selected brain areas (basal forebrain (31); ventral midbrain (32)) in which the transmitter build-up of the cells expressing the NT-1 receptor had previously been identified (cholinergic in the former, dopaminergic in the latter), providing a means to assess, using immunohistochemistry for choline acetyltransferase and tyrosine hydroxylase, respectively, the selectivity of fluoNT labeling patterns for cells expressing the NT-1.

In both regions, the distributional pattern of fluo-NT labeling varied according to the duration of the wash-out after ligand application. Between 5 and 10 min after application of fluo-NT, the labeling was intense and distributed throughout the neuropil over neuronal perikarya and processes alike (Figure 7). Thirty and $60 \mathrm{~min}$ after application of ligand, the labeling had markedly increased over neuronal perikarya but had almost completely disappeared from the surrounding 
Figure 8 - Double staining of COS-7 cells transfected with CDNA encoding the NT-1 receptor with fluo-NT (A) and acridine orange (B). Fluo-NT labeling was carried out for $30 \mathrm{~min}$ at $37^{\circ} \mathrm{C}$. Cells were then rinsed and further incubated for 1 min with acridine orange. Note that both labels are co-localized within the same intracellular organelles, indicating that fluo-NT is internalized within acidic compartments. $\mathrm{n}$, Nucleus. Scale bar: $10 \mu \mathrm{m}$.
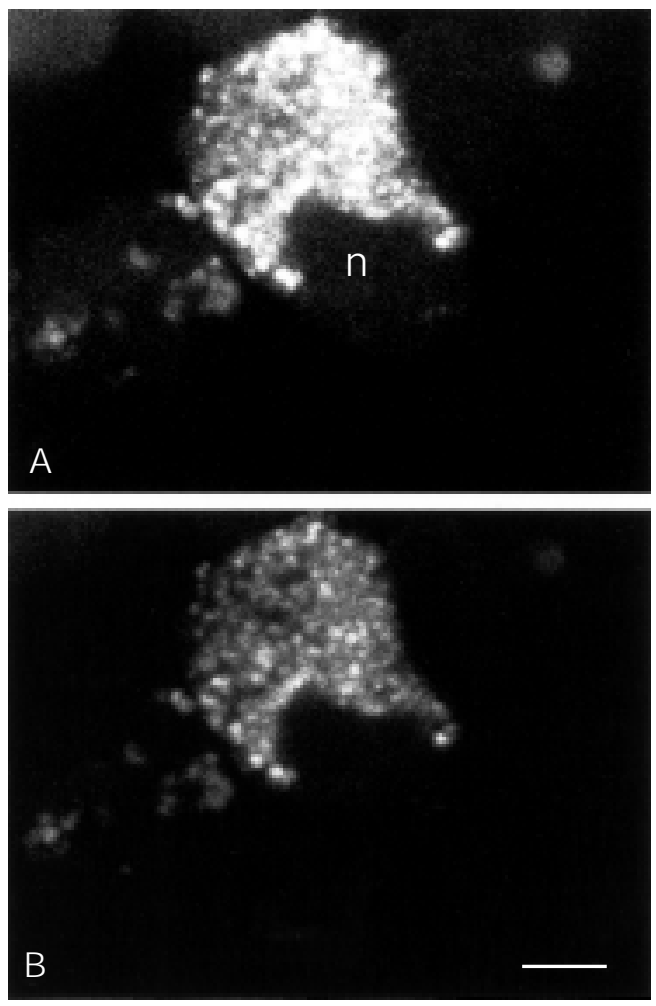

processes. By single optical sectioning, intracellular labeling was detected in the form of small, intensely fluorescent particles which increased in size but decreased in number with time (Figure 7). These "hot spots" also got closer with time to the nucleus of the cell as seen in transfected cells. In slices incubated with an excess of native NT, no labeling was observed over either region except for a diffuse reactivity of intraparenchymal capillaries. Similarly, no tissue labeling was observed after incubation with fluorescein isothiocyanate alone.

The concomitant decrease in neuropil labeling and increase in specific fluo-NT observed over time suggest that internalization occurring at the level of the dendritic tree is rapidly followed by an intracellular mobilization of internalized molecules. The migration and remodeling of intracellular internalization compartments with time further suggest that, as in transfected cells, NT is internalized via classical internalization pathways.

\section{Identification of endocytic compartments}

One of the advantages of fluorescent peptides is that they may be used in conjunction with either other fluorescent markers or with immunofluorescence for double localization studies. We have resorted to both of these approaches to determine whether the internalization of fluorescent peptides witnessed in both transfected epithelial cells and rat brain slices proceeded through the classical, clathrin-mediated endocytic pathway.

We first examined the $\mathrm{pH}$ of the internalization compartments, as classical endosomes are known to be more acidic than the surrounding cytoplasm (33). For this purpose, we resorted to acridine orange, a vital dye documented to accumulate selectively in compartments with low internal $\mathrm{pH}$ values (34). COS-7 cells transfected with the NT-1 receptor were first incubated for $30 \mathrm{~min}$ at $37^{\circ} \mathrm{C}$ in the presence of $10 \mathrm{nM}$ fluo-NT. Cells were then rinsed, rapidly stained with acridine orange ( $20 \mu \mathrm{M}, 1 \mathrm{~min}$ at room temperature), rinsed again and observed under the confocal microscope. After $30 \mathrm{~min}$ of incubation, fluo-NT formed, as described above, numerous intracellular hot spots (Figure $8 \mathrm{~A}$ ). All of fluo-NT-labeled structures also exhibited strong acridine orange staining (Figure 8B) indicating that they were highly acidic and that they could therefore correspond to early endosomes, late endosomes or lysosomes.

To further distinguish between these different possibilities, and also to monitor the migration of the ligand within endocytic compartments with time, we combined in the same cell system the visualization of fluoNT with the immunohistochemical detection of marker proteins which may be used to distinguish between different endocytic compartments. Thus, at short time intervals (0$20 \mathrm{~min}$ ) following incubation of the transfected cells with fluo-NT, most of the intracellular ligand was detected in compartments 
that immunostained positively for Rab 5, a small GTP-binding protein known to be associated with early endosomes $(35,36)$. These results are congruent with those of our acridine orange experiments and indicate that fluo-NT is internalized via clathrin-coated pits and that it subsequently proceeds along the endosomal pathway.

Because of the acidic environment of endosomes, this process is known to result in a dissociation of receptor-ligand complexes. Following dissociation, internalized receptors may be either targeted to lysosomes for degradation or recycled back to the plasma membrane (37). To confirm that receptorligand complexes were indeed dissociated within the acidic environment of the endosomal system, we followed in parallel the fate of fluo-NT and that of immunolabeled NT-1 in COS-7 cells transfected with an NTR1VSV epitope construct (25). As predicted from current models, receptor and ligand molecules were co-localized within the same compartments at short time intervals (0-20 min; Figure 9) but were totally dissociated at longer time points $(>20 \mathrm{~min})$. As current biochemical data suggest that the NT receptor is not recycled $(38,39)$, it is likely that the dissociated receptor is being targeted to lysosomes for intracellular degradation.

\section{Conclusions}

The present data demonstrate the applicability of confocal microscopy to the visualization of specifically bound fluorescent peptides for studying the "static" distribution of cell surface and/or intracellular receptors both in cell cultures and in tissue sections, as well as for monitoring the "dynamic" fate of bound fluorescent ligands in these same types of preparations maintained in vivo.

Using this approach, we were able to confirm that the binding of neuropeptides to cell surface G-protein-coupled receptors induces clustering of receptor-ligand com-

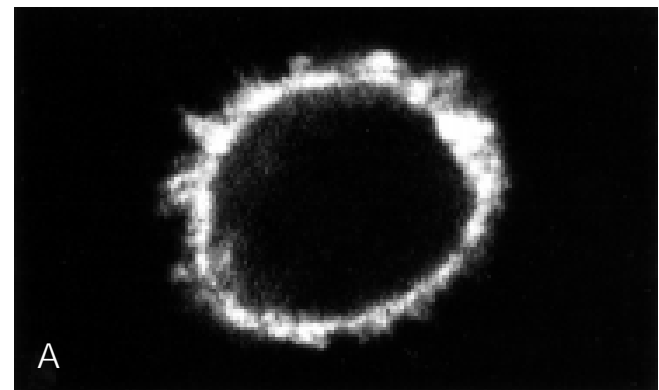

Figure 9 - Dual localization of internalized fluo-NT and immunoreactive NT-1 receptor in COS-7 cells transfected with CDNA encoding the NT-1 receptor tagged with an immunogenic epitope (VSV). Cells were incubated for $5 \mathrm{~min}$ with $20 \mathrm{nM}$ fluo-NT, fixed with paraformaldehyde and immunolabeled for the tagged NT-1 receptor. Note that at this short time point there is complete overlap in the distribution of ligand $(A)$ and receptor (B) confirming that internalization implicates receptorligand complexes. Scale bar: 5 $\mu \mathrm{m}$.

plexes through lateral diffusion of the receptors in the plasma membrane. We were also able to demonstrate in both neurons and heterologous expression systems that this clustering is followed by internalization and intracellular migration of receptor-ligand complexes. This intracellular routing is both receptor- and cell-specific and presumably reflects various possible fates of the ligand (degradation $v s$ externalization; intracellular signaling?) and of the receptor (degradation vs recycling; endosomal signaling?). Our results demonstrate that in the case of NT, the internalization of the peptide is clathrin dependent, proceeds through classical endosomal pathways and involves dissociation of receptor-ligand complexes within late endosomal compartments. In neurons, this process is characterized by a mobilization of newly formed endosomes first from sites of internalization along neuronal processes to the cell body and second from the periphery of the cell body to the perinuclear zone. In both neurons and epithelial cells, endosomal compartments increase in size but decrease in number during their migration from the periphery to the center of the cell, suggesting that formation of multivesicular bodies/late 
endosomes occurs through fusion of early endosomes.

Work is now in order to determine the role of neuropeptide internalization in the central nervous system and, particularly, to investigate whether this internalization process mainly subserves the sensitization/desensitization and availability of cell surface receptors (40) or whether it also plays a role in neural signaling (for a review, see 37 ). It will also be critical to determine the fate of internalized ligand in terms of enzymatic inactivation, targeting to intracellular compartments and/or externalization in the extracellular space. It is likely, if the past is any indication of the future, that confocal microscopy will continue to play a critical role in answering these questions.

\section{Acknowledgments}

We thank Christian Charbonneau for photographic assistance and Beverley Lindsay for typing the manuscript.

\section{References}

1. McGrath J C, Arribas S \& Daly CJ (1996). Fluorescent ligands for the study of receptors. Trends in Pharmacological Sciences, 17: 393-399.

2. Bunnett NW, Dazin PF, Payan DG \& Grady EF (1995). Characterisation of receptors using cyanine 3-labeled neuropeptides. Peptides, 16: 733-740.

3. Hazum E, Chang $\mathrm{KJ} \&$ Cuatrecasas $\mathrm{P}$ (1980). Cluster formation of opiate (enkephalin) receptors in neuroblastoma cells: differences between agonists and antagonists and possible relationships to biological functions. Proceedings of the National Academy of Sciences, USA, 77: 3038-3041.

4. Nouel D, Gaudriault G, Houle M, Reisine T, Vincent J P, Mazella J \& Beaudet A (1997). Differential internalization of somatostatin in COS-7 cells transfected with SST1 and SST2 receptor subtypes: a confocal microscopic study using novel fluorescent somatostatin derivatives. Endocrinology, 138: 296-306.

5. Gaudriault G, Nouel D, Dal Farra C Beaudet A \& Vincent J P (1997). Receptorinduced internalization of selective peptidic $\mu$ and $\delta$ opioid ligands. J ournal of Biological Chemistry, 272: 2880-2888.

6. Faure MP, Gaudreau P, Shaw I, Cashman NR \& Beaudet A (1994). Synthesis of a biologically active fluorescent probe for labeling neurotensin receptors. J ournal of Histochemistry and Cytochemistry, 42: 755-763.

7. Alonso A, Faure MP \& Beaudet A (1994). Neurotensin promotes oscillatory bursting behavior and is internalized in basal forebrain cholinergic neurons. J ournal of
Neuroscience, 14: 5778-5792.

8. Atlas D \& Levitzki A (1977). Probing of beta-adrenergic receptors by novel fluorescent beta-adrenergic blockers. Proceedings of the National Academy of Sciences, USA, 74: 5290-5294.

9. Heithier $H$, Hallmann $D$, Boege $F$, Reilander $\mathrm{H}$, Dees $\mathrm{C}$, J aeggi KA, ArndtJ ovin D, J ovin TM \& Helmreich EJ (1994). Synthesis and properties of fluorescent beta-adrenoceptor ligands. Biochemistry, 33: 9126-9134.

10. Velazquez $\mathrm{J} \mathrm{L}$, Thompson $\mathrm{CL}$, Barnes $\mathrm{J} \mathrm{r}$ EM \& Angelides KJ (1989). Distribution and lateral mobility of GABA/benzodiazepine receptors on nerve cells. J ournal of Neuroscience, 9: 2163-2169.

11. Balice-Gordon RJ \& Lichtman J W (1993). In vivo observations of pre- and postsynaptic changes during the transition from multiple to single innervation at developing neuromuscular junction. J ournal of Neuroscience, 13: 834-855.

12. Wang $Y, G u$ Q, Mao F, Haugland RP \& Cynader MS (1994). Activity-dependent expression and distribution of $\mathrm{M} 1$ muscarinic ACh receptors in visual cortex neuronal cultures. J ournal of Neuroscience, 14: 4147-4158.

13. Ariano MA, Monsma J r FJ, Barton AC, Kang HC, Haugland RP \& Sibley DR (1989). Direct visualization and cellular localization of D1 and D2 dopamine receptors in rat forebrain by use of fluorescent ligands. Proceedings of the National Academy of Sciences, USA, 86: 8570-8578.

14. Barton AC, Kang $H C$, Rinaudo MS, Monsma J $r$ FJ, Stewart-Fram RM, Macinko J r J A, Haugland RP, Ariano MA
\& Sibley DR (1991). Multiple fluorescent ligands for dopamine receptors. I. Pharmacological characterization and receptor selectivity. Brain Research, 547: 199-207.

15. Garland AM, Grady EF, Payan DG, Vigna SR \& Bunnett NW (1994). Agonist-induced internalization of the substance $P$ $\left(\mathrm{NK}_{1}\right)$ receptor expressed in epithelial cells. BiochemistryJ ournal, 303: 177-186.

16. Grady EF, Garland AM, Gamp PD, Lovett M, Payan DG \& Bunnett NW (1995). Delineation of the endocytic pathway of substance $P$ and its seven-transmembrane domain NK1 receptor. Molecular Biology of the Cell, 6: 509-524.

17. Hein L, Meinel L, Pratt RE, Dzau VJ \& Kobilka BK (1997). Intracellular trafficking of angiotensin II and its $\mathrm{AT}_{1}$ and $\mathrm{AT}_{2}$ receptors: evidence for selective sorting of receptor and ligand. Molecular Endocrinology, 11: 1266-1277.

18. Ashworth R, Yu R, Nelson EJ , Dermer $S$, Gershengorn MC \& Hinkle PM (1995). Visualization of the thyrotropin-releasing hormone receptor and its ligand during endocytosis and recycling. Proceedings of the National Academy of Sciences, USA, 92: 512-516.

19. Hazum E, Chang KJ, Shechter $Y$, Wilkinson S \& Cuatrecasas P (1979). Fluorescent and photo-affinity enkephalin derivatives: preparation and interaction with opiate receptors. Biochemical and Biophysical Research Communications, 88 : 841-846.

20. Emmerson PJ, Archer S, El-Hamouly W Mansour A, Akil $H$ \& Medzihradsky $F$ (1997). Synthesis and characterization of 4,4-difluoro-4-bora-3a,4a-diaza-s-indacene 
(BODIPY)-labeled fluorescent ligands for the mu opioid receptor. Biochemical Pharmacology, 54: 1315-1322.

21. Roettger BF, Rentsch RU, Pinon D, Holicky E, Hadac E, Larkin J M \& Miller LJ (1995). Dual pathways of internalization of the cholecystokinin receptor. J ournal of Cell Biology, 128: 1029-1041.

22. Hazum E, Cuatrecasas $P$, Marian J \& Conn PM (1980). Receptor-mediated internalization of fluorescent gonadotropin-releasing hormone by pituitary gonadotropes. Proceedings of the National Academy of Sciences, USA, 77: 6692-6695.

23. Lutz W, Sanders $M$, Salisbury J \& Kumar R (1990). Internalization of vasopressin analogs in kidney and smooth muscle cells: evidence for receptor-mediated endocytosis in cells with $V_{2}$ or $V_{1}$ receptors. Proceedings of the National Academy of Sciences, USA, 87: 6507-6511.

24. Grady EF, Slice LW, Brant WO, Walsh J H, Payan DG \& Bunnett NW (1995). Direct observation of endocytosis of gastrin releasing peptide and its receptor. J ournal of Biological Chemistry, 270: 4603-4611.

25. Chabry J, Botto J M, Nouel D, Beaudet A, Vincent J P \& Mazella J (1995). Thr-422 and Tyr-424 residues in the carboxyl terminus are critical for the internalization of the rat neurotensin receptor. J ournal of Biological Chemistry, 270: 2439-2442.

26. Faure MP, Labbé-J ullié $C$, Cashman NR, Kitabgi P \& Beaudet A (1995). Binding and internalization of neurotensin in hybrid cells derived from septal cholinergic neurons. Synapse, 20: 106-116.

27. Nouel D, Faure MP, Saint Pierre JA,
Alonso R, Quirion R \& Beaudet A (1997). Differential binding profile and internalization process of neurotensin via neuronal and glial receptors. J ournal of Neuroscience, 17: 1795-1803.

28. Mazella J, Leonard K, Chabry J , Kitabgi P, Vincent J -P \& Beaudet A (1991). Binding and internalization of iodinated neurotensin in neuronal cultures from embryonic mouse brain. Brain Research, 564: 249-255.

29. Young WS \& Kuhar MJ (1979). A new method for receptor autoradiography: ${ }^{3} \mathrm{H}$ opioid receptor labeling in mounted tissue sections. Brain Research, 179: 255270.

30. Epelbaum J, Moyse E, Tannenbaum G, Kordon C \& Beaudet A (1989). Combined autoradiographic and immunohistochemical evidence for an association of somatostatin binding sites with growth hormone-releasing factor containing nerve cell bodies in the rat arcuate nucleus. J ournal of Neuroendocrinology, 1: 109115.

31. Faure MP, Alonso A, Nouel D, Gaudriault G, Dennis M, Vincent J P \& Beaudet A (1995). Somatodendritic internalization and perinuclear targeting of neurotensin in the mammalian brain. J ournal of Neuroscience, 15: 4140-4147.

32. Faure MP, Nouel D \& Beaudet A (1995). Axonal and dendritic transport of internalized neurotensin in rat mesostriatal dopaminergic neurons. Neuroscience, 68: 519529.

33. Mellman I, Fuchs R \& Helenius A (1986). Acidification of the endocytic and exocytic pathways. Annual Review of Biochemistry, 55: 663-700.

34. Anderson RGW \& Orci L (1988). A view of acidic intracellular compartments. J ournal of Cell Biology, 106: 539-544.

35. Chavrier P, Parton RG, Hauri HP, Simons K \& Zerial M (1990). Localization of low molecular weight GTP binding proteins to exocytic and endocytic compartments. Cell, 62: 317-329.

36. Simons K \& Zerial M (1993). Rab proteins and the road maps for intracellular transport. Neuron, 11: 789-799.

37. Bevan AP, Drake PG, Bergeron JJM \& Posner BI (1996). Intracellular signal transduction: the role of endosomes. Trends in Endocrinology and Metabolism, 7: 13-21.

38. Tumer J T, J ames-Kracke MR \& Camden J M (1990). Regulation of the neurotensin receptor and intracellular calcium mobilization in HT29 cells. J ournal of Pharmacology and Experimental Therapeutics, 253: 1049-1056.

39. Hermans $E$, Vanisberg MA, Geurts $M \&$ Maloteaux J M (1997). Down-regulation of neurotensin receptors after ligand-induced internalization in rat primary cultured neurons. Neurochemistry International, 31: 291-299.

40. Dournaud $P$, Boudin $H$, Schonbrunn A, Tannenbaum GS \& Beaudet A (1998). Interrelationships between somatostatin sst2A receptors and somatostatin-containing axons in rat brain: evidence for regulation of cell surface receptors by endogenous somatostatin. J ournal of Neuroscience, 18: 1056-1071. 